\title{
トゴットメバルのアセトン可溶性脂質について*
}

\author{
露木英男・成瀬宇平 \\ (1962 年 12 月 8 日受理)
}

\section{THE ACETONE-SOLUBLE LIPID OF SEBASTODES JOYNERI}

\section{Hideo TsUYUKI and Uhei NARUSE**}

The characteristics of the acetone-soluble lipid contained in "Toggotomebaru", Sebastodes joyneri, were studied. The lipid contained in ten fresh sample fish was extracted with acetone immediately after catch. The acetone-soluble lipid was obtained in the yield of $2.24 \%$ from the fresh fish. The lipid had the characteristcs as given in Table 2.

The mixed fatty acids, prepared from the acetone-soluble lipid by alkali-hydrolysis, were separated into three portions, solid, unsaturated and highly unsaturated acids, with a combination of lead salt-ethanol and lithium salt-acetone methods and their methyl esters were fractionated as usual through the modified E.H.P. column.

According to calculation of HILDITCH, the component fatty acids of the acetone-soluble lipid are shown in Table 7. The paper chromatography indicated the presence of myristic, palmitic, stearic, arachidic, zoomaric, oleic, linoleic and linolenic acids.

トゴットメバル，Sebastodes joyneri (Fig. 1)，はメバル科に属する比較的小型の魚であつて，内湾に多

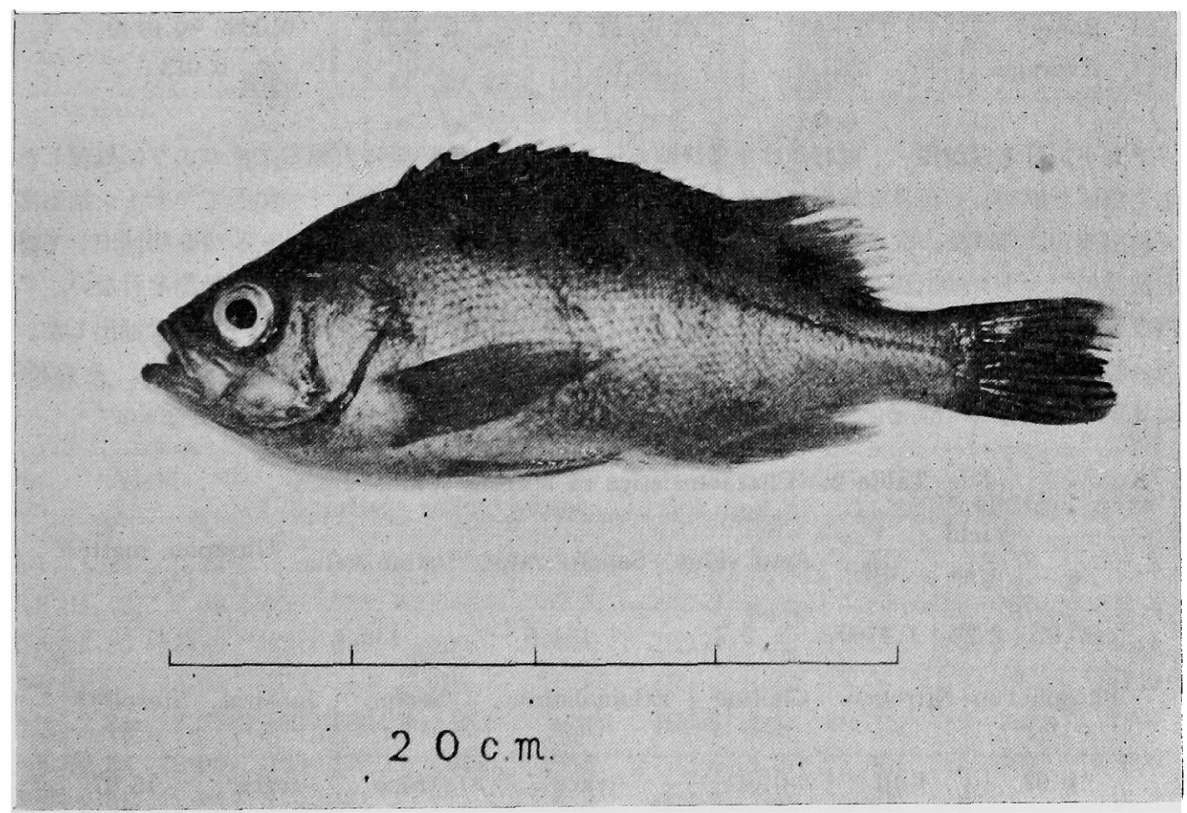

Fig. 1. TOGGOTOMEBARU, Sebastodes joyneri.

* 本研究の大要は昭和 37 年度日本水産学会秋季大会（長崎大学）に执いて発表した。

** 日本大学農獣医学部水産化学教室 (Lab. Fish. Chem., Coll. Agr. and Vet. Med., Nihon Univ., Tokyo, Japan). 
く生急し，成魚は体長 $20 \mathrm{~cm}$ 以上に達する。魚体は橙赤色であつて 5 条り黑褐色横带がある。本種はいそ 兴であつて春期の産䀦期には沿岸に現われ，冬は深層へ移動する。日本备地で産するが，南日本にやや多い。 鮮魚は食用に供するが，すこぶる美味である。トゴットメハル油に関する睡往の文献は見当たらないが，同

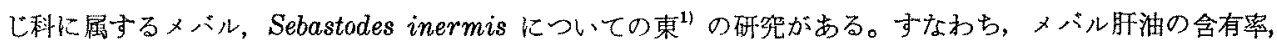
一般性状をメバル科に属する他の奥種と比較研究したものである。メバル科に属する他の魚種すなおちバラ メヌケ Sebastodes macrochir, マメヌケ Sebastodes flammeus, オサガ Sebastodes iracundusなどにつ

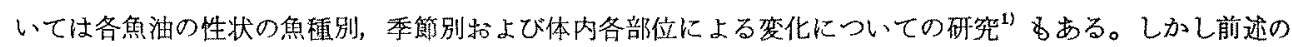
よ5にトゴットメバルの脂質については未だ研究されていないので，著者らは本㮔のアセトン可溶性脂質に ついて研究した。

\section{実験および結果}

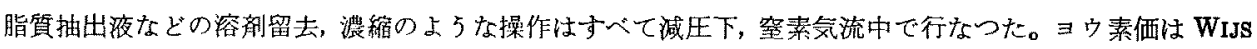
法，空素はミクロケルダール法リンは BEVERIDGE and JOHNSON の方法2)、エタノールフミン特よびセ

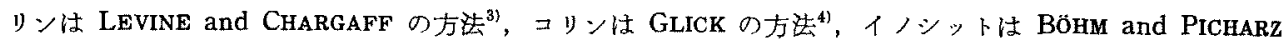
の方法 ${ }^{5} に よ り$ 測定した。

1. 試料魚試料魚は昭和 36 年 4 月 24 日, 小田原市沼岸で潐爑した 10 尾 (2586 g)のトゴットメ ハルであり，それらの体重，体長，体幅和よび肥満度は Table 1 に示すと扬りである。

Table 1. Size of sample fish.

\begin{tabular}{l|c|c|c|c}
\hline Sample fish & $\begin{array}{c}\text { Body weight } \\
(\mathrm{g})\end{array}$ & $\begin{array}{c}\text { Body length } \\
(\mathrm{cm})\end{array}$ & $\begin{array}{c}\text { Body width } \\
(\mathrm{cm})\end{array}$ & $\begin{array}{c}\text { Degree of fatness } \\
\left(\mathrm{g} / \mathrm{cm}^{3}\right)\end{array}$ \\
\hline Range & $171-431$ & $23.5-32.0$ & $7.0-9.5$ & $0.0085-0.0149$ \\
Average & 285.6 & 26.8 & 8.0 & 0.013 \\
\hline
\end{tabular}

2.アセトン可溶性脂稘 試料魚は魚獲後直ちに冷蔵し，4時閔後に実験室で次のよ5に処理した。す

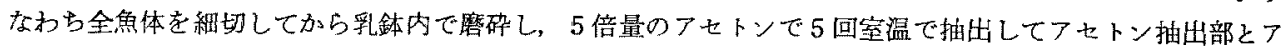
せトン抽出残分に分けた。次に後者のアせトン抽出残分を 5 倍量の95\%フルコールで5回抽出して得た抽 出物を前述のアセトン抽出部と合一し，さらにこの合一部を 5 倍舅のアセトンで 3 回抽出を行ない, アセト

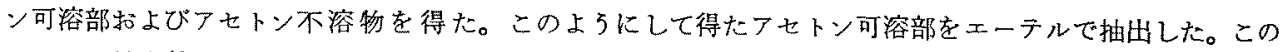
エーテル抽出物に 5 倍量のアセトンを加充て 3 回抽出を行ない, アセトン可溶性脂質を得た。その性状は Table 2 に示すと招りである。

Table 2. Characteristics of acetone-soluble lipid*.

\begin{tabular}{c|c|c|c|c|c|c|c|}
\hline \multicolumn{2}{|c|}{ Yield } & Acid value & Sapon. value & Iodine value & $\begin{array}{c}\text { Unsapon. matter } \\
(\%)\end{array}$ \\
\hline $\mathbf{g}$ & $\% * *$ & $n_{0}^{20}$ & 2.7 & 184.6 & 144.1 & 2.41 \\
\hline $\begin{array}{c}\text { Phosphorus } \\
(\%)\end{array}$ & $\begin{array}{c}\text { Nitrogen } \\
(\%)\end{array}$ & $\begin{array}{c}\text { Choline } \\
(\%)\end{array}$ & $\begin{array}{c}\text { Ethanolamine } \\
(\%)\end{array}$ & $\begin{array}{c}\text { Serine } \\
(\%)\end{array}$ & $\begin{array}{c}\text { Inositol } \\
(\%)\end{array}$ & $\begin{array}{c}\text { Sterol*** } \\
(\%)\end{array}$ \\
\hline 0.03 & 0.01 & 0.01 & trace & trace & trace & 15.97 \\
\hline
\end{tabular}

* Sample fish $\rightarrow \rightarrow$ Acetone extract $\rightarrow$ Residue $\rightarrow$ Ethanol extract $-\rightarrow$ Acetone extract $\rightarrow$ Ethyl-ether extract $\rightarrow$ Acetone extract (Acetone-soluble lipid)

** \% of acetone-soluble lipid in fresh fish.

**** $\%$ of sterol in unsaponificiable matter by digitonine method, 
Table 3. Properties of fatty acids and their methyl esters.

\begin{tabular}{|c|c|c|c|c|c|}
\hline \multirow{2}{*}{ Acids } & \multirow{2}{*}{$\begin{array}{l}\text { Yield } \\
(\%)\end{array}$} & \multirow{2}{*}{$\begin{array}{c}\text { Neutralization } \\
\text { value }\end{array}$} & \multirow{2}{*}{$\begin{array}{l}\text { Iodine } \\
\text { value }\end{array}$} & \multicolumn{2}{|c|}{ Methyl ester } \\
\hline & & & & $\begin{array}{l}\text { Sapon. } \\
\text { value }\end{array}$ & $\begin{array}{l}\text { Iodine } \\
\text { value }\end{array}$ \\
\hline Solid fatty acids & 16.24 & 206.6 & 8.3 & 196.5 & 7.6 \\
\hline Lowly unsaturated fatty acids & 45.61 & 196.9 & 96.9 & 188.7 & 92.5 \\
\hline Highly unsaturated fatty acids & 38.15 & 182.5 & 286.2 & 174.6 & 281.8 \\
\hline
\end{tabular}

3. 脂肪酸 アセトン可溶性脂質 $55.0 \mathrm{~g}$ 常法により $2 \mathrm{~N}-\mathrm{KOH}$ アルコール液でケン化し，不ケン化 物をエーテルで除去後，混合脂肪酸（中和価 193.9，ヨウ素洒 156.2）を得た。次にこの混合脂肪酸を鉛堭

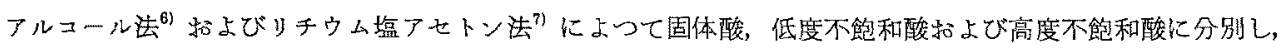
それぞれの性状を湘定した (Table 3)。さらにこれら3種の脂肪酸（固体酸，低度不飽和酸，高度不飽和酸）

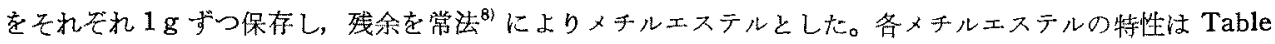
3 に示すと橎である。次にこれらのエステルをそれぞれ E.H.P. 分留塔 ${ }^{9}$ (落長 $60 \mathrm{~cm}$ ) を用いて精密に 減王分留し，各留分のケン化洒和よびョウ素価を湘定した (Table 4〜6)。

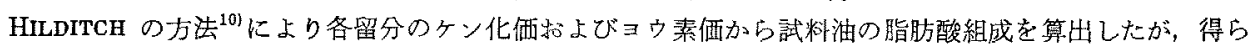

Table 4. Fractional distillation of methyl ester of saturated fatty acids.

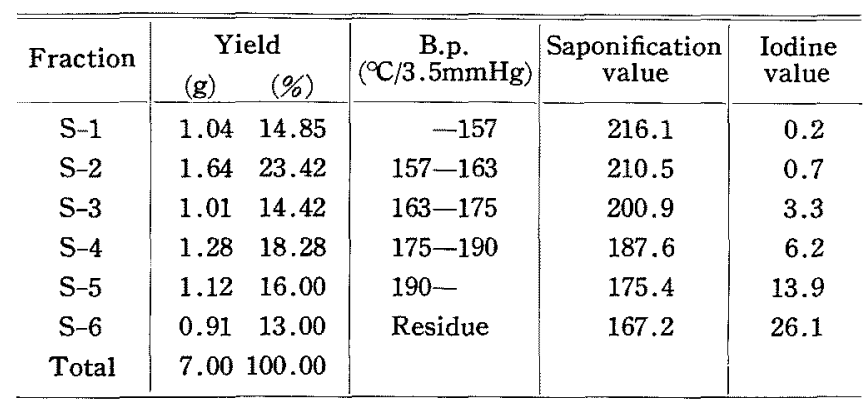

Table 5. Fractional distillation of ester of lowly unsaturated fatty acids.

\begin{tabular}{|c|c|c|c|c|c|}
\hline $\begin{array}{c}\text { Frac- } \\
\text { tion }\end{array}$ & $\begin{array}{c}\mathrm{Yi} \\
(\mathrm{g})\end{array}$ & eld & $\underset{\left({ }^{\circ} / 2 \mathrm{~mm} \mathrm{Hg}\right)}{\text { B.p. }}$ & $\begin{array}{c}\text { Sapon. } \\
\text { value }\end{array}$ & $\begin{array}{c}\text { Iodine } \\
\text { value }\end{array}$ \\
\hline LU-1 & 1.25 & 6.94 & -155 & 213.4 & 33.2 \\
\hline $\mathrm{LU}-2$ & 1.42 & 7.88 & $155-158$ & 203.5 & 59.8 \\
\hline LU-3 & 2.19 & 12.16 & $158-160$ & 194.9 & 73.4 \\
\hline LU-4 & 2.35 & 13.05 & $160-163$ & 188.6 & 79.7 \\
\hline LU -5 & 2.84 & 15.77 & $163-166$ & 186.1 & 86.1 \\
\hline $\mathrm{LU}-6$ & 2.33 & 12.38 & $166-175$ & 182.8 & 94.8 \\
\hline $\mathrm{LU}-7$ & 2.04 & 11.33 & $175-181$ & 177.3 & 106.3 \\
\hline LU-8 & 1.55 & 8.61 & $181-192$ & 175.2 & 116.5 \\
\hline LU-9 & 1.38 & 7.66 & $192-$ & 173.7 & 121.1 \\
\hline $\begin{array}{c}\text { LU-10 } \\
\text { Total }\end{array}$ & $\begin{array}{r}0.75 \\
18.00\end{array}$ & $\begin{array}{r}4.22 \\
100.00\end{array}$ & Residue & 168.5 & 143.7 \\
\hline
\end{tabular}

Table 6. Fractional distillation of methyl ester of highly unsaturated fatty acids.

\begin{tabular}{|c|c|c|c|c|c|}
\hline \multirow{2}{*}{$\begin{array}{c}\text { Frac- } \\
\text { tion }\end{array}$} & \multicolumn{2}{|c|}{ Yield } & \multirow{2}{*}{$\begin{array}{c}\text { B.p. } \\
\left({ }^{\circ} \mathrm{C} / 1 \mathrm{mmHg}\right)\end{array}$} & \multirow{2}{*}{$\begin{array}{l}\text { Sapon. } \\
\text { value }\end{array}$} & \multirow{2}{*}{$\begin{array}{l}\text { Iodine } \\
\text { value }\end{array}$} \\
\hline & (g) & $(\%)$ & & & \\
\hline HU-1 & 1.03 & 6.86 & -158 & 202.2 & 117.5 \\
\hline HU-2 & 1.26 & 8.40 & $158-163$ & 193.3 & 125.1 \\
\hline HU-3 & 1.85 & 12.33 & $163-170$ & 186.1 & 245.2 \\
\hline HU-4 & 2.44 & 16.26 & $170-189$ & 178.9 & 272.7 \\
\hline HU-5 & 2.86 & 19.06 & $189-195$ & 172.6 & 299.3 \\
\hline HU-6 & 2.67 & 17.80 & $195-200$ & 160.0 & 330.3 \\
\hline $\mathrm{HU}-7$ & 1.95 & 13.00 & $200-$ & 158.3 & 337.1 \\
\hline HU -8 & 0.94 & 6.29 & Residue & 157.4 & 284.4 \\
\hline Total & 15.00 & 100.00 & & & \\
\hline
\end{tabular}


Table 7. Component acids of sample oil.

\begin{tabular}{c|c|c|c|c}
\hline Acids & $\begin{array}{c}\text { Solid } \\
(15.55 \%)\end{array}$ & $\begin{array}{c}\text { Lowly unsat. } \\
(51.12 \%)\end{array}$ & $\begin{array}{c}\text { Highly unsat. } \\
(33.33 \%)\end{array}$ & $\begin{array}{r}\text { Total } \\
(100 \%)\end{array}$ \\
\hline Saturated: & & & & 21.52 \\
Myristic & 1.04 & 0.57 & & 1.66 \\
Palmitic & 5.88 & 4.17 & & 10.05 \\
Stearic & 3.51 & 3.44 & & 6.95 \\
Arachidic & 2.51 & 0.31 & & 2.82 \\
Behenic & 0.04 & & & 0.04 \\
\hline Unsaturated & & & & 78.48 \\
$\mathrm{C}_{14}$ & & $0.23(-2.0 \mathrm{H})$ & & $0.23(-2.0 \mathrm{H})$ \\
$\mathrm{C}_{16}$ & $0.51(-2.0 \mathrm{H})$ & $4.40(-2.0 \mathrm{H})$ & $5.33(-2.1 \mathrm{H})$ & $10.23(-2.0 \mathrm{H})$ \\
$\mathrm{C}_{18}$ & $0.13(-2.0 \mathrm{H})$ & $19.94(-2.2 \mathrm{H})$ & $3.91(-4.9 \mathrm{H})$ & $23.98(-2.6 \mathrm{H})$ \\
$\mathrm{C}_{20}$ & $0.18(-2.0 \mathrm{H})$ & $17.04(-2.6 \mathrm{H})$ & $12.29(-6.8 \mathrm{H})$ & $30.51(-4.5 \mathrm{H})$ \\
$\mathrm{C}_{22}$ & $0.70(-2.0 \mathrm{H})$ & $1.02(-3.0 \mathrm{H})$ & $4.86(-7.1 \mathrm{H})$ & $6.58(-5.8 \mathrm{H})$ \\
$\mathrm{C}_{24}$ & & & $6.95(-9.8 \mathrm{H})$ & $6.95(-9.8 \mathrm{H})$ \\
\hline
\end{tabular}

Table 8. $R f$ value of 2,4-dinitrophenyl hydrazone of component saturated acid acetal ester.

\begin{tabular}{l|c|c|c|c}
\hline \hline Acids & Myristic & Palmitic & Stearic & Arachidic \\
\hline Standard & 0.37 & 0.31 & 0.24 & 0.14 \\
Sample & 0.35 & 0.32 & 0.23 & 0.16
\end{tabular}

Paper: Toyo No. $2(40 \times 40 \mathrm{~cm})$,

Moving phase: Methanol-acetic acid-alcohol (10:2:1),

Stationary phase: Tetralin, Ascending at $20^{\circ} \mathrm{C}$.

Table 9. $R f$ value of mercuric acetate complexes of methyl ester of component lowly unsaturatee fatty acids.

\begin{tabular}{l|c|c|c|c|c|c}
\multicolumn{1}{c|}{ Acids } & Zoomaric & \multicolumn{2}{c|}{ Oleic Eicosenoic } & Erucic & Linoleic & Linolenic \\
\hline Standard & 0.27 & 0.16 & 0.09 & 0.05 & 0.52 & 0.71 \\
Sample & 0.29 & 0.17 & 0.11 & 0.05 & 0.50 & 0.73 \\
\hline
\end{tabular}

Paper: Toyo No. $2(40 \times 40 \mathrm{~cm})$,

Moving phase: $90 \%$ methanol-Acetic acid-Tetralin $(30: 1: 3)$,

Stationary phase: Tetralin, Ascending at $20^{\circ} \mathrm{C}$.

Table 10. $R f$ value of 2, 4-dinitrophenyl hydrazone of hydrogenated component highly unsaturated acid acetal ester.

\begin{tabular}{l|c|c|c|c|c}
\hline \multicolumn{1}{c|}{ Acids } & Myristic & Palmitic & Stearic & Arachidic & Behenic \\
\cline { 2 - 6 } Standard & 0.37 & 0.31 & 0.24 & 0.14 & 0.12 \\
Sample & - & - & 0.24 & 0.16 & 0.11 \\
\hline
\end{tabular}

Method is the same as in Table 8 .
れた結果は Table 7 に示すと括 りである。

次に井上らの方法 ${ }^{11)}$ に上りもノ ブロムアセトンで固体酸のフセト ールエステルを合成し，さらにそ の固体酸エステルをエタノールに 加渭溶解し，これに，2，4-ジニト ロフェニルヒドラジンをとかした $2 N-\mathrm{HCl}$ メタノール温溶液のやや 渦量索加えて放给し, 少量の水を 加光て折出するてセトールエステ

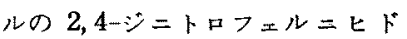
ラゾンをろ別し，それを $2 \%$ そッ ゼン溶液としてペーパークロマト グラフィーを行なつた (Table 8)。 また低度不飽和酸を常法により メチルメステルとしこれれ野田

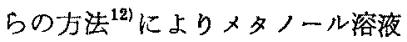
中で䣫酸第二氷銀を付加し，この 付加物に逝相ペーパークロマトグ ラフィーを行なつた（Table 9)。

最後に高度不飽和酸を水添して 得られた飽和酸を前述の固体酸と

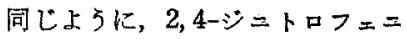
ルヒドラゾンとしてペーパークロ マトグラフィーにより検索し，ス 
テアリン酸, アラキジン酸括よびペヘニン酸の存在を認めた（Table 10）。

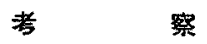

Table 2 より明らかなように,トゴットメバルのアセトン可溶性脂質は微量のリン脂質を含んでいると考

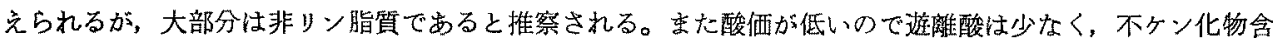
有率が低いのでグリセリドが大部分であると思われる。トゴットメバルのアセトン可溶性脂質の脂肪酸組成 (計算値) は高度真空分留法によれば，Table 7 に示式と呿りである。この結果をみ机ば明らかなよらに，

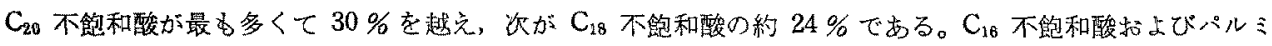
チン酸はそれそれれ $10 \%$ である。 $\mathrm{C}_{24}$ 高度不飽和酸誩よび $\mathrm{C}_{22}$ 高度不飽和酸はそれぞれ 6 そ\%であつて両 者を合わせると $14 \%$ 弱である。アラキジン酸とミリスチン酸はとれぞれ 1 3\%できわめて少ない。べ ニン酸， $\mathrm{C}_{14}$ 不飽和酸はコン跡程度である。な放，ペーパークロマトグラフィーによつて，トゴットメバル のアセトン可溶性脂質にはミリスチン酸, パルミチン酸, ステフリン酸, エイコセン酸, エルミン酸,リ, 一ル酸、リノレン酸の存在が推定された。

総括

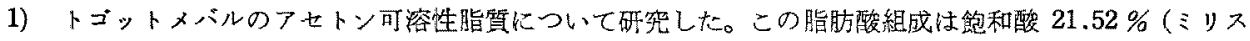
チン酸 $1.66 \%$ ，パルミチン酸 $10.05 \%$ ，ステフリン酸 $6.95 \%$ ，フラキジン酸 $2.82 \%$ ，ペニン酸 0.04 \%) 拉上び不飽和酸 $78.48 \%\left\{\mathrm{C}_{14}\right.$ 酸 $(-2.0 \mathrm{H}) 0.23 \%, \mathrm{C}_{16}$ 酸 $(-2.0 \mathrm{H}) 10.23 \%, \mathrm{C}_{18}$ 酸 $(-2.6 \mathrm{H})$ $23.98 \%, \mathrm{C}_{20}$ 酸 $(-4.5 \mathrm{H}) 30.51 \%, \mathrm{C}_{22}$ 酸 $(-5.8 \mathrm{H}) 6.58 \%, \mathrm{C}_{24}$ 酸 $(-9.8 \mathrm{H}) 6.95 \%$ である。

2）ペーパークロマトグラフィーによれば，トゴットメバルのフセトン可容性脂贊にはミリスチン酸，パ ルミチン酸、ステアリン酸、アラキジン酸、ゾーマリン酸, オレイン酸, エイコセン酸、エルシン酸, リ， ール酸、リノレン酸が含まれているすのと思われる。

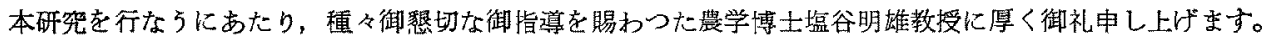

文献

1) 東 秀雄：水産副産物の化学的研究（水座社，東京)， p. 112 (1942).

2) J.M. R. Beveridse and S. E. Johnson: Can. J. Res., Sec. Sec. E., 27, 159 (1949).

3) C. Levine and E. Chargaff: J. Biol. Chem., 192, 465 (1951).

4) D. GLICK: J. Biol. Chem., 158, 643 (1944).

5) P. Böhm and G. PICharz: Z. physiol. Chem., 298, 110 (1954).

6) T.P. HILDITCH: "The Chemical Constitution of NaturalFats" Ird El. Revised, p. 574 (1956).

7) 过本満丸: 工化，23，272(1920).

8) T.P. HIDDITCH: "The Chemical Constitution of Natural Fats" grd Ed. Revised" p. 575 (1956).

9) H. E. LONGENECKeR: J. Soc. Chem. Ind., 56, $199 \mathrm{~T}$ (1937).

10) T.P. Hrdich: "The Chemical Constitution of Natural Fats" 3rd Ed. Revised, p. 609 (1956).

11) 井上吉之・平山 修・野田方次郎：油化学, 5, 16 (1956).

12) 野田万次郎・平山 修・井上吉之：農化，30，106 (1956). 